\title{
FRACTIONAL COINTEGRATION AND REAL EXCHANGE RATES
}

\author{
Guglielmo Maria Caporale \\ South Bank University, London
}

Luis A. Gil-Alana

Humboldt Universitat zu Berlin

\author{
June 2000
}

\begin{abstract}
This paper uses fractional integration and cointegration in order to model the DM/dollar and the yen/dollar real exchange rates in terms of both monetary and real factors, more specifically real interest rate and labour productivity differentials. We find that whilst the individual series may be integrated of order 1, their long-run relationship might have a fractionally cointegrated structure. This means that mean reversion occurs, consistently with the findings of other studies. However, it also indicates, in contrast to such studies, that the cointegrating relationship possesses long memory. In other words, the error correction term responds slowly to shocks, implying that deviations from equilibrium are long-lived. It appears that only a combination of real and monetary variables can accurately track down the movements of real exchange rates.
\end{abstract}

Keywords: Real Exchange Rates; Fractional Integration; Fractional Cointegration

JEL Classification: C22, C32, F30, F41

Corresponding author: Professor Guglielmo Maria Caporale, South Bank University, Business School, 103 Borough Road, London SE1 0AA, UK. Tel: +44 (0)20 78157012 . Fax: +44 (0)20 7815 8226. E-mail: g.m.caporale@sbu.ac.uk 


\section{Introduction}

Long-run theories of the real exchange rate have alternatively focused on real or monetary factors as the main determinants of its equilibrium level (see Froot and Rogoff, 1994; Rogoff, 1996 and MacDonald, 1995, for an extensive review of the literature). Caporale and Pittis (1998) argue that only a combination of the two can account for the actual behaviour of real exchange rates. In particular, in their view monetary factors are responsible for the long-lived deviations from equilibrium, whilst real factors are the fundamentals determining the long-run level. In other words, "sticky price" open macro models (see, e.g., Dornbusch, 1976) can provide a rationale for the observed persistence of the shocks and slow mean reversion, whilst productivity differentials can be seen as the driving force behind real exchange rates in the long run (see Balassa, 1964 and Samuelson, 1964). A similar idea informs the model by Mussa (1982), where the movement of the real exchange rate is decomposed into an equilibrium component driven by real factors, and a transitory one which is associated with changes in the nominal exchange rate regime.

Caporale and Pittis (1998) show that the cointegrating vector includes real exchange rates, real interest differentials and productivity differentials, which are all found to be I(1) variables. Treating interest rate differentials as I(1) series might appear surprising, as the existence of long-run capital flows equalising real rates implies that they should be $\mathrm{I}(0)$ (see Meese and Rogoff, 1988). The rationale for the inclusion in the cointegrating set is that they might be fractionally integrated variables. Such processes exhibit long memory and high persistence (see Granger and Joyeaux, 1980), and therefore it is necessary to include them in the long-run specification in order to obtain a stable relationship.

A number of recent studies have been able to find mean reversion in real exchange rates (see the references in the survey by Rogoff, 1996; Lothian, 1997; Edison et al., 1997). However, standard cointegration analysis restricts the error correction term to be an $\mathrm{I}(0)$ 
process, which is not persistent. In this paper we argue that a fractionally integrated and cointegrated structure might be more appropriate for modelling real exchange rates. Specifically, the error correction term might respond to shocks more slowly than implied by classical cointegration, and the equilibrium errors might behave as a fractionally integrated series displaying slow mean reversion. In other words, the error correction term might exhibit long memory, so that deviations from equilibrium are highly persistent. Under these circumstances, a fractional cointegrating relationship provides a much better understanding of the behaviour of the series of interest. Using this methodology we find that real exchange rates are in fact fractionally cointegrated with real interest rate and labour productivity differentials.

The structure of the paper is as follows. Section 2 briefly reviews the literature on real exchange rates. Section 3 defines the concepts of fractional integration and cointegration, summarising some of the techniques for estimating and testing the long-memory parameter. In Section 4 these techniques are applied to the DM/dollar and yen/dollar real exchange rates. Finally, Section 5 contains some concluding remarks.

\section{A brief review of the literature on real exchange rates}

Numerous empirical studies have tested for the existence of a long-run relationship between real exchange rates and real interest differentials. Most of them have been unsuccessful in finding such a relationship. For instance, Campbell and Clarida (1987) concluded that the innovation variance of real interest differentials is too small to account for the large swings in real exchange rates, which appear to be driven instead by other permanent shocks (see Huizinga, 1987), most likely of real nature (see Clarida and Galli, 1994). This raises the question whether the key relationship is between the temporary components of these two variables, as argued by Baxter (1994). Meese and Rogoff (1988) also failed to find cointegration, a result which they attributed to the omission of some relevant variables such as 
the expected future real exchange rate. Blundell-Wignall and Browne (1991) argue that including the equilibrium rate results in cointegration. The opposite conclusion is reached by Edison and Pauls (1993). Lothian and Taylor $(1996,1997)$ point out that the problem might simply be one of low power in small samples of the test statistics used - mean reversion can be found over long time spans. Alternatively, panel unit root methods can be used, which again produce stronger evidence in favour of a long-run relationship between real exchange rates and real interest differentials (see MacDonald et al., 1997).

The above line of empirical research follows on from monetary models of the real exchange rate (see, e.g. Dornbusch, 1976 and Frankel, 1979). An alternative line of thought stresses the role of real factors as long-run determinants of the real exchange rate. The seminal papers are due to Balassa (1964) and Samuelson (1964), who essentially argued that productivity differentials between traded and non-traded good sectors will lead to an appreciation of the real exchange rate in countries with higher growth, even if the law of one price holds for traded goods. Using panel cointegration methods, Chinn (1997) finds some evidence in favour of productivity-based explanations, whilst Ito et al. (1996) and Isard and Symanski (1996) do not. The share of the cumulated current account relative to the GNP is included in the cointegration regression in other studies, with results which are sometimes supportive of cointegration (see Blundell-Wignall and Browne, 1991), though not always (see, e.g., Edison and Pauls, 1993).

As mentioned above, some recent studies have been able to find mean reversion in real exchange rates (see, e.g., Rogoff, 1996; Lothian, 1997; Edison et al., 1997), in some cases without incorporating either labour productivity or real interest rate differentials. However, the discrete options $\mathrm{I}(1)$ and $\mathrm{I}(0)$ on which they are based are rather restrictive, especially in the case of real exchange rates, which might respond very slowly to innovations. Consequently, we will adopt below a statistical framework based on fractional integration and 
cointegration, which allows the adjustment to equilibrium between markets to take a long time ${ }^{1}$.

There are a few examples in the exchange rate literature of studies using fractional integration/cointegration techniques. For instance, Diebold, Husted and Rush (1991) applied fractionally ARIMA models to real exchange rates under the gold standard, providing evidence of mean reversion. Cheung and Lai (1993) found evidence of fractional cointegration between the real exchange rates of five industrialised countries, by testing for the order of the integration of the residuals from the cointegrating regression. Baillie and Bollerslev (1994a) also reported that exchange rates are tied together through a long-memory I(d)-type process (i.e., they are fractionally cointegrated); similarly, Baillie and Bollerslev (1994b) concluded that the forward premium exhibits long memory, implying that the forward rate and the spot rate are linked by a long-run fractionally cointegrating relationship.

By contrast, the present article focuses on the determination of real exchange rates by examining, in a multivariate context, their relationship with labour productivity and interest rate differentials. The multivariate nature of our analysis differentiates it also from a recent study by Engel and Kim (1999), who, like us, attempt to evaluate the role of both monetary and real factors. However, theirs is a univariate model of the real exchange rate, which is decomposed into a highly persistent transitory component switching between three different states, and a permanent one which is homoscedastic and has low variance. Engel and Kim (1999) claim that the former is closely related to monetary phenomena, and the latter to relative per capita output levels, but these hypotheses are not tested within a multivariate framework.

\footnotetext{
${ }^{1}$ Another recent strand of the literature focuses on non-linearities. For instance, Michael et al. (1997) argue that cointegration tests might be biased against finding mean reversion because they ignore the effects of transaction costs. They suggest representing the nonlinear adjustment process in terms of an exponential smooth transition autoregressive (ESTAR) model, which implies highly persistent deviations from equilibrium, but a meanreverting dynamic process. ESTAR models have also been estimated by O'Connell (1998), and Taylor and Peel (2000), the latter finding that they approximate well the nonlinearity in the series describing deviations of the nominal exchange rate from the monetary fundamental equilibrium level.
} 


\section{Fractional integration and cointegration}

Unit roots or I(1) processes are extremely specialised models for describing the nonstationary character of macroeconomic time series. They became popular after Nelson and Plosser's (1982) influential paper, which, following Box and Jenkins (1970), argued that the fluctuations in the level of many economic time series were better explained in terms of "stochastic" rather than "deterministic" models. Commonly, the unit root behaviour is nested in autoregressive (AR) alternatives; however, any number of mathematical forms can be constructed that nest a unit root. One of these models is the class that allows for a "fractional" degree of integration. To illustrate this in the case of a scalar time series $x_{t}, t=1,2, \ldots$, suppose $\mathrm{v}_{\mathrm{t}}$ is an unobservable covariance stationary sequence with spectral density that is bounded and bounded away from zero at the origin, and

$$
(1-\mathrm{L})^{\mathrm{d}} \mathrm{x}_{\mathrm{t}}=\mathrm{v}_{\mathrm{t}}, \quad \mathrm{t}=1,2, \ldots,
$$

where $\mathrm{L}$ is the lag operator. The process $\mathrm{v}_{\mathrm{t}}$ could itself be a stationary and invertible ARMA sequence, with an exponentially decaying autocovariance. This property can be said to characterise a "weakly autocorrelated" process. When $\mathrm{d}=0, \mathrm{x}_{\mathrm{t}}=\mathrm{v}_{\mathrm{t}}$, so a "weakly autocorrelated" $\mathrm{x}_{\mathrm{t}}$ is allowed for. When $\mathrm{d}=1, \mathrm{x}_{\mathrm{t}}$ has a unit root, while for a general integer $\mathrm{d}$, $\mathrm{X}_{\mathrm{t}}$ has $\mathrm{d}$ unit roots. However, $\mathrm{d}$ need not be an integer, a case analysed by Adenstedt (1974) and numerous subsequent authors. For $0<\mathrm{d}<1 / 2, \mathrm{x}_{\mathrm{t}}$ is still stationary, but its lag- $\mathrm{j}$ autocovariance $\gamma_{j}$ decreases very slowly, like the power law $j^{2 d-1}$ as $j \rightarrow \infty$, and so the $\gamma_{j}$ are non-summable. When $v_{t}$ is an $\operatorname{ARMA}(p, q), x_{t}$ has been called an $\operatorname{ARFIMA}(p, d, q)$ process, adopting the form:

$$
\phi(\mathrm{L})(1-\mathrm{L})^{\mathrm{d}} \mathrm{x}_{\mathrm{t}}=\theta(\mathrm{L}) \varepsilon_{\mathrm{t}}, \quad \mathrm{t}=1,2, \ldots,
$$

where $\phi$ and $\theta$ are polynomials of orders $p$ and q respectively, with all zeroes of $\phi(L)$ outside the unit circle, and all zeroes of $\theta(\mathrm{L})$ outside or on the unit circle, and $\varepsilon_{\mathrm{t}}$ is a white noise. 
The distinction between $\mathrm{I}(\mathrm{d})$ processes with $\mathrm{d}=1$ and $\mathrm{d}<1$ is important from an economic point of view: if a variable is an $\mathrm{I}(\mathrm{d})$ process with $\mathrm{d} \in[0.5,1)$, it will be covariance nonstationary but mean-reverting since an innovation will have no permanent effect on its value. This is in contrast to an $\mathrm{I}(1)$ process which will be both covariance nonstationary and not mean-reverting, in which case the effect of an innovation will persist forever.

In view of the preceding remarks it is of interest to estimate the fractional differencing parameter $\mathrm{d}$, along with the other parameters related to the ARMA representation. Sowell (1992) analysed the exact maximum likelihood estimates of the parameters of the fractionally ARIMA (ARFIMA) model (2) in the time domain, using a recursive procedure that allows a quick evaluation of the likelihood function. This procedure will be implemented in the empirical application carried out in Section 4. Similarly, Robinson (1994) proposes LM tests for testing unit roots and other forms of nonstationary hypotheses, embedded in fractional alternatives. Specifically, the null hypothesis to be tested is:

$$
\mathrm{H}_{\mathrm{o}}: \theta=0
$$

in the model

$$
(1-L)^{d+\theta} x_{t}=v_{t}, \quad t=1,2, \ldots
$$

where $\mathrm{d}$ can be 1 but also any other real given value, and $\mathrm{v}_{t}$ is a (possibly weakly autocorrelated) $\mathrm{I}(0)$ processes. The test statistic takes the form:

$$
\bar{r}=\left(\frac{T^{1 / 2}}{\bar{\sigma}^{2}}\right) \bar{A}^{-1 / 2} \bar{a},
$$

where $\mathrm{T}$ is the sample size and

$$
\begin{gathered}
\bar{a}=\frac{-2 \pi}{T} \sum_{j=1}^{T-1} \psi\left(\lambda_{j}\right) g\left(\lambda_{j} ; \bar{\tau}\right)^{-1} I\left(\lambda_{j}\right) \\
\bar{A}=\frac{2}{T}\left(\sum_{j=1}^{T-1} \psi\left(\lambda_{j}\right)^{2}-\sum_{j=1}^{T-1} \psi\left(\lambda_{j}\right) \varepsilon\left(\lambda_{j}\right)^{\prime}\left(\sum_{j=1}^{T-1} \varepsilon\left(\lambda_{j}\right) \varepsilon\left(\lambda_{j}\right)^{\prime}\right)^{-1} \sum_{j=1}^{T-1} \varepsilon\left(\lambda_{j}\right) \psi\left(\lambda_{j}\right)\right),
\end{gathered}
$$


$\bar{\sigma}^{2}=\sigma^{2}(\bar{\tau})=\frac{2 \pi}{T} \sum_{j=1}^{T-1} g\left(\lambda_{j} ; \bar{\tau}\right)^{-1} I\left(\lambda_{j}\right) ; \quad \psi\left(\lambda_{j}\right)=\log \left|2 \sin \frac{\lambda_{j}}{2}\right| ; \quad \varepsilon\left(\lambda_{j}\right)=\frac{\partial}{\partial \tau} \log g\left(\lambda_{j} ; \bar{\tau}\right)$.

$\mathrm{I}\left(\lambda_{\mathrm{j}}\right)$ is the periodogram of $\bar{v}_{t}=(1-\mathrm{L})^{\mathrm{d}} \mathrm{x}_{\mathrm{t}}$, evaluated at $\lambda_{\mathrm{j}}=2 \pi \mathrm{j} / \mathrm{T}$, and $\mathrm{g}$ above is a known function, coming from the spectral density of $\bar{v}_{t}$,

$$
f\left(\lambda_{j} ; \tau\right)=\frac{\sigma^{2}}{2 \pi} g\left(\lambda_{j} ; \tau\right)
$$

and $\bar{\tau}$ is obtained by minimising $\sigma^{2}(\tau)$. The main advantage of these tests is that the limit distribution is standard, unlike most unit root tests (see, e.g., Dickey and Fuller, 1979) where a nonstandard asymptotic distribution is obtained and critical values have to be calculated case by case by means of Montecarlo simulations. In particular, Robinson (1994) showed that under certain regularity conditions:

$$
\overline{\mathrm{r}} \rightarrow \mathrm{N}(0,1) \quad \text { as } \mathrm{T} \rightarrow \infty .
$$

Thus, a one-sided $100 \alpha \%$-level test of (3) against the alternative: $\mathrm{H}_{1}: \theta>0$ is given by the rule: 'Reject $H_{0}$ if $\bar{r}>Z_{\alpha}$ ', where the probability that a standard normal variate exceeds $Z_{\alpha}$ is $\alpha$, and, conversely, an approximate one-sided $100 \alpha \%$-level test of (3) against the alternative: $H_{1}: \theta<0$ is given by the rule: 'Reject $H_{0}$ if $\bar{r}<-Z_{\alpha}$ '.

Furthermore, he shows that the above tests are efficient in the Pitman sense, i.e. that against local alternatives of form: $\mathrm{H}_{\mathrm{a}}: \theta=\delta \mathrm{T}^{-1 / 2}$, for $\delta \neq 0$, the limit distribution is normal with variance 1 and mean which cannot (when $\mathrm{v}_{\mathrm{t}}$ is Gaussian) be exceeded in absolute value by that of any rival regular statistic. An empirical application of these tests using US historical annual data can be found in Gil-Alana and Robinson (1997) and, other versions of the tests, involving monthly and quarterly data, are presented in Gil-Alana (1999) and Gil-Alana and Robinson (2000) respectively.

Having discussed fractional integration and the methods for estimating and testing I(d) statistical models, we next introduce the concept of fractional cointegration. The components 
of a (nx1) vector $X_{t}$ are said to be fractionally cointegrated of order $d, b,\left(X_{t} \sim C I(d, b)\right)$ if a): all components of $X_{t}$ are integrated of order $d\left(X_{i t} \sim I(d)\right)$, and $\left.b\right)$ : there exists a vector $r(r \neq 0)$ such that $N_{t}=r^{\prime} X_{t}$ is integrated of order $d-b\left(N_{t} \sim I(d-b)\right)$ with $b>0 .{ }^{2}$ The vector $r$ is called the cointegrating vector and $\mathrm{r}^{\prime} \mathrm{X}_{\mathrm{t}}$ will represent an equilibrium constraint operating on the longrun component of $\mathrm{X}_{\mathrm{t}}$.

The values of $d$ and b can be tested by carrying out Robinson's (1994) tests on the original series and the residuals, adopting a testing procedure which follows a methodology similar to that proposed by Engle and Granger (1987) (for more details, see Gil-Alana, 1997). Thus, we can initially test the order of integration of the original series, and if all of them have the same order of integration (say a unit root), we can test the degree of integration of the estimated residuals of the cointegrating structure. In this context, the non-rejection of the null hypothesis that the order of integration of the estimated residuals is equal to that of the original series will imply that the series are not cointegrated. On the other hand, rejections of the null in favour of alternatives with a smaller degree of integration will give us evidence of fractional cointegration of a certain degree.

Cheung and Lai (1993) extended Stock's (1987) consistency results for the least squares estimate of the cointegrating parameters to the case of fractional cointegration, where the rate of convergence varies according to the cointegration order. Their results justify using Robinson's (1994) tests for testing the integration order of the equilibrium errors. However, it should be pointed out that, even though the asymptotic results are still valid, given that the residuals used are not actually observed but obtained from minimising the residual variance of the cointegrating regression, in finite samples the residual series might be biased towards stationarity. Thus, we would expect the null to be rejected more often than suggested by the normal size of Robinson's (1994) tests. Therefore, the empirical size of these tests for

\footnotetext{
${ }^{2}$ For a more general definition of fractional cointegration, allowing different integration orders for each series, see Marinucci and Robinson (1998).
} 
cointegration in finite samples has to be obtained using a simulation approach. Montecarlo experiments indicate that they perform better than standard tests, regardless of whether fractional or AR alternatives are considered (see Gil-Alana, 1997). ${ }^{3}$

\section{Data and empirical analysis}

For the empirical analysis we used quarterly series on the nominal exchange rate of DM and yen vis-à-vis the US dollar, consumer price indices, and ten-year government bond yields, covering the period from $1975 \mathrm{q} 1$ to $1998 \mathrm{q} 4$. The data source is the IMF's International Financial Statistics. Real interest rates were constructed using alternative measures of expected inflation, namely a 1, 4, and 12 quarter central moving average, in addition to previous period's inflation (see Edison and Pauls, 1993). As the differences were minor, only the results based on the last measure mentioned are discussed. Finally, OECD data on employment (number of employees) and nominal GDP expressed in US dollars (converted into real GDP using PPP rates) were used to calculate productivity.

The first step in the empirical analysis is to investigate the order of integration of the three individual series (i.e., real exchange rates, real interest rate differentials, and labour productivity differentials) for both countries, Germany and Japan.

\section{(Table 1 about here)}

Table 1 summarises the results of Sowell's (1992) estimation procedure of ARFIMA models like (2). Specifically, we estimated different ARFIMA(p, d, q) models with $p$ and $q$ smaller than or equal to 3 . Table 1 displays, for each series, the best model specification according to some likelihood criteria (AIC and SIC) ${ }^{4}$. Note that the Sowell's (1992) procedure

\footnotetext{
3 An alternative approach is advocated by Dueker and Startz (1998), who suggest a testing methodology based on joint estimates of the fractional orders of integration of a cointegrating vector and its parent series. However, they do not quantify the size properties of their test relative to two-step tests by means of Monte Carlo experiments.

4 To assure stationarity and following standard practise, the models were estimated in first differences and then converted back to levels.
} 
is based on maximum likelihood, and thus conventional tests based on the statistic $(d-\hat{d}) / S E(\hat{d})$ can be performed. We see that for practically all the series the unit root null hypothesis $(\mathrm{d}=1)$ cannot be rejected. The only exceptions are labour productivity in Japan (with an integration order of 1.60), and the yen/dollar exchange rate, which, according to the SIC should be modelled as an $\operatorname{ARFIMA}(0,1.29,0)$, but according to the AIC should be specified as an $\operatorname{ARFIMA}(2,0.94,3)$, in the latter case the unit root hypothesis not being rejected. For the remaining series, the orders of integration oscillate between 0.98 and 1.17, and in all cases the null $\mathrm{d}=1$ cannot be rejected.

Next, the tests of Robinson (1994) were applied in (4) for different values of $d$ and different specifications for the disturbances $\mathrm{v}_{\mathrm{t}}$. Across Tables 2-7, we report values of $\bar{r}$ in (5) with $\mathrm{d}=0,0.25, \ldots,(0.25), \ldots, 1.75$ and 2 , thus testing for a unit root $(\mathrm{d}=1)$ but also including a test for stationarity $(\mathrm{d}=0.5)$ and for $\mathrm{I}(2)(\mathrm{d}=2)$ as well as other fractional possibilities.

\section{(Tables 2 and 3 about here)}

Starting with the real exchange rates, we see in Table 2 that for the DM/dollar rate, the null is always rejected when $d=0$. On the other hand, testing $H_{o}$ (3) with $d=1$, the null is never rejected regardless of how we model the $\mathrm{I}(0)$ disturbances and, though we also observe some other non-rejection values, the lowest statistic across the different values of $\mathrm{d}$ practically always occurs in the unit root case. Similarly, for the yen/dollar real exchange rate (see Table 3 ), the non-rejection values of (3) occur when $d=0.75,1$ and 1.25 , with the lowest statistics appearing in all cases when $d=1$. Therefore, we can conclude that the DM/dollar and the yen/dollar real exchange rates may both contain a unit root.

\section{(Tables 4 and 5 about here)}

Tables 4 and 5 report the results of the tests of Robinson (1994) for the labour productivity differentials in Germany and Japan respectively. Starting with Germany (in Table 4), we see that, as in the previous tables, all the non-rejection values occur when $d=$ 
$0.75,1$ and 1.25, and, again, the lowest statistics appear in all cases when $d=1$, i.e., in the unit root case. Concerning the results in Japan (see Table 5), the unit root null hypothesis cannot be rejected for any type of disturbances, though, if the disturbances are modelled as $\operatorname{AR}(1)$ or $\operatorname{AR}(2)$ processes, lower statistics are obtained when $d>1$.

(Tables 6 and 7)

The tests of Robinson (1994) were finally applied to the real interest rate differentials. The results for Germany, reported in Table 6 , are rather mixed. Thus, if $\mathrm{v}_{\mathrm{t}}$ is white noise, $\mathrm{H}_{\mathrm{o}}$ (3) cannot be rejected when $d=1$ and 1.25. If $v_{t}$ is AR, the non-rejection values of $d$ range between 0.75 and 1.25, and modelling $\mathrm{v}_{\mathrm{t}}$ in terms of a seasonal AR process of form: $v_{t}=\sum_{j=1}^{p} \phi_{j} v_{t-4 j}+\varepsilon_{t}$, with $\mathrm{p}=1$ and 2 , the only non-rejection value occurs at $\mathrm{d}=1.25$. The results for the Japanese interest rate differentials, given in Table 7, indicate that the unit root null is never rejected, the lowest statistics appearing at $d=1$ for white noise and seasonal AR $\mathrm{v}_{\mathrm{t}}$, and at $\mathrm{d}=0.75$ for non-seasonal AR's. ${ }^{5}$

To sum up, the univariate analysis indicates that all series may be integrated of order 1, though other fractional orders of integration, lower than or higher than 1 , were also plausible in some cases. Note that Robinson's (1994) approach generates simply computed diagnostics for departures from any real $\mathrm{d}$. Thus, it is not at all surprising that, when fractional hypotheses are entertained, some evidence supporting them appears because this might happen even when the unit root model is highly suitable. Moreover, given the uncertainty about the presence of a unit roots, several other unit root tests based on autoregressive alternatives (such as the ones suggested by Dickey and Fuller, 1979, and Phillips and Perron, 1988) were also performed, obtaining in all cases evidence in favour of a unit root. In the case of interest differentials, this finding is in contrast to growth theories predicting that real

\footnotetext{
5 Higher autoregressive orders were also considered in both, the seasonal and the non-seasonal cases, and the results were similar to those reported in the paper.
} 
interest rates are I(0), so that the differential should be too. This is also implied by one of the central propositions of international finance theory, namely the equalisation of real rates. However, most empirical studies fail to reject the null of a unit root (see, e.g., Meese and Rogoff, 1988), though a recent paper by Wu and Zhang (1996) reports that nominal rates in OECD countries are stationary.

After establishing the presence of unit roots in the univariate series, we examine the possibility of their being fractionally cointegrated. We run the OLS regression of real exchange rates against productivity and interest rate differentials, obtaining the following results for Germany:

$$
E R_{t}=4.32-0.035 I D_{t}-0.079 P D_{t}
$$

and for Japan:

$$
E R_{t}=-0.287-0.034 I D_{t}-0.0020 P D_{t},
$$

where $\mathrm{ER}_{\mathrm{t}}$ represents the real exchange rate, and $\mathrm{ID}_{\mathrm{t}}$ and $\mathrm{PD}_{\mathrm{t}}$ correspond to interest and productivity differentials respectively. Testing now the order of integration of the estimated residuals from the above regressions using the tests of Robinson (1994), we obtain the results displayed in Tables 8 and 9.

\section{(Tables 8 and 9 about here)}

We initially concentrate on testing (3) in (4) with $d=1$ and $x_{t}$ replaced by the residuals estimated above, using the critical values obtained in Gil-Alana (1997). The critical value against the alternative $\mathrm{H}_{1}: \theta<0$ at the $5 \%$ significance level for a sample of the size considered here is -2.10 , obtaining rejections of $\mathrm{H}_{0}$ if $\mathrm{v}_{\mathrm{t}}$ is an $\mathrm{AR}$ process. However, as mentioned in Section 3, given the consistency of the cointegrating parameters and the desirable properties of Robinson's (1994) tests, we can still rely on the asymptotic critical values given by the Normal distribution. It can be seen from Tables 8 and 9 that the results vary substantially depending on how we model the I(0) disturbances. Thus, if they are white noise or seasonally autoregressive, we find non-rejection values for $\mathrm{d}=0.80,0.90$ and 1 in 
the case of Germany, and $d=0.90$ and 1 for Japan. In these cases, the lowest statistics are obtained when $d=0.90$ for Germany and $d=1$ for Japan. However, a totally different picture emerges if the disturbances follow non-seasonal autoregressive processes. In particular, the non-rejection values always take place when $\mathrm{d}$ is smaller than or equal to 0.60 , and the lowest statistics occur when $d=0.10$ with $\operatorname{AR}(1)$ and when $d=0.50$ with $\operatorname{AR}(2)$ disturbances for Germany, and when $d=0.30$ in Japan. We also see that the null hypothesis $d=0$ is practically always rejected. The only case in which it is not rejected is that of Germany with AR(1) disturbances. This means that the classical cointegration specification is practically always rejected, especially in the case of Japan.

In brief, if the disturbances are autoregressive, the residuals from the cointegrating regressions are fractionally integrated, and thus a fractionally cointegrated relationship does exist between real exchange rates, and labour productivity and real interest rate differentials in both countries.

\section{Conclusions}

The determinants of the DM/dollar and yen/dollar real exchange rates have been examined in this paper by means of fractional integration and cointegration techniques. We have shown that both monetary and real factors are relevant. Specifically, real exchange rates are fractionally cointegrated with real interest rate and labour productivity differentials. The univariate analysis, based on Sowell's (1992) ML estimation procedure and Robinson's (1994) testing procedure, both indicate that all series might be I(1). Further inspection by means of AR-based unit root tests leads to the conclusion that they are in fact I(1). The multivariate analysis reveals that in both countries the series are hardly cointegrated if the disturbances are white noise or seasonal autoregressions; however, when the disturbances are modelled as non-seasonal autoregressions, the orders of integration of the estimated residuals 
fluctuate between 0 and 0.50 in the case of Germany and between 0.10 and 0.60 in the case of Japan.

Other studies had also found mean reversion, sometimes without relying on a combination of monetary and real factors, but, by adopting a classical cointegration framework, had imposed a relatively quick adjustment process. By contrast, we show that the cointegrating relationship possesses long memory. In other words, the equilibrium errors exhibit slow mean reversion, i.e. they respond very slowly to shocks, implying that deviations from equilibrium are persistent. Such a long-memory relationship provides a better understanding of the behaviour of real exchange rates. Our results confirm those reported by Caporale and Pittis (1998), who argued, in the same spirit as Mussa (1982), that both sticky price open macro models and real models of the exchange rate are missing important factors, and that only a combination of monetary and real variables can accurately track down the movements of real exchange rates. Similar conclusions were reached by Engel and Kim (1999), albeit by estimating a univariate time series model.

The research reported in this paper can be extended in many ways. For instance, the order of integration of the estimated residuals from the cointegrating regression can be investigated further by means of other, recently developed, semiparametric approaches (see, e.g., Robinson, 1995a, 1995b, and Marinucci and Robinson, 1998). Also, finite-sample critical values for Robinson's (1994) tests can be calculated using bootstrapping techniques. Finally, formal tests can be conducted to verify the statistical relevance of both labour productivity and interest rate differentials, i.e. to show that indeed they belong to the cointegrating relationship. Work in these directions is under way at present. 


\section{References}

Adenstedt, R.K. (1974), "On large-sample estimation for the mean of a stationary random sequence”, Annals of Statistics, 2, 1095-1107.

Baillie, R.T. and T. Bollerslev (1994a), "Cointegration, fractional cointegration, and exchange rate dynamics", Journal of Finance, 49, 737-745.

Baillie, R.T. and T. Bollerslev (1994a), "The long memory of the forward premium", Journal of International Money and Finance, 13, 565-571.

Balassa, B. (1964), "The purchasing power doctrine: a reappraisal", Journal of Political Economy, 72, 584-596.

Baxter, M. (1994), "Real exchange rates and real interest differentials: have we missed the business-cycle relationship?", Journal of Monetary Economics, 33, 5-37.

Blundell-Wignall, A. and F. Browne (1991), "Increasing financial market integration, real exchange rates and macroeconomic adjustment", Working Paper no. 96, OECD Department of Economics and Statistics.

Box, G.E.P. and G.M. Jenkins (1970), Time Series Analysis: Forecasting and Control, Holden Day, San Francisco.

Campbell, J.Y. and R.H. Clarida (1987), "The dollar and real interest rates", in K. Brunner and A.H. Meltzer (eds.), Carnegie-Rochester Conference Series on Public Policy, 27, 103140.

Caporale, G.M. and N. Pittis (1998), "Revisiting the long-run relationship between real exchange rates and real interest differentials: a productivity differential approach", D.P. no.16-98, Centre for Economic Forecasting, London Business School.

Cheung Y.W. and K.S. Lai (1993), "A fractional cointegration analysis of purchasing power parity”, Journal of Business and Economic Statistics, 11, 103-112.

Chinn, M.D. (1997), "The usual suspects? Productivity and demand shocks and Asia-Pacific real exchange rates", NBER Working Paper no. 6108.

Clarida, R.H. and J. Galli (1994), "Sources of real exchange-rate fluctuations: how important are nominal shocks?", Carnegie-Rochester Conference Series on Public Policy, 41, 1-56.

Deuker, M. and R. Startz (1998), "Maximum-likelihood estimation of fractional cointegration with an application to US and Canadian bond rates", Review of Economics and Statistics, 420426.

Dickey, D.A. and W.A. Fuller (1979), "Distribution of the estimators for autoregressive time series with a unit root", Journal of the American Statistical Association, 74, 427-431.

Diebold, F.X., S. Husted and M. Rush (1991), "Real exchange rates under the gold standard", Journal of Political Economy, 99, 1252-1271. 
Dornbusch, R. (1976), "Expectations and exchange rate dynamics", Journal of Political Economy, 84, 1161-1176.

Edison, H.J. and D. Pauls (1993), "A re-assessment of the relationship between real exchange rates and real interest rates: 1974-1990", Journal of Monetary Economics, 31, 165-187.

Engel, C. and C.J. Kim (1999), "The long-run US/UK real exchange rate", Journal of Money, Credit and Banking, 31, 3, 335-356.

Edison, H.J., Gagnon, J.E. and W.R. Melick (1997), "Understanding the empirical literature on purchasing power parity: the post Bretton Woods era", Journal of International Money and Finance, 16, 1, 1-17.

Engle, R.F. and C.W.J. Granger (1987), "Co-integration and error correction: representation, estimation, and testing", Econometrica, 55, 2, 251-276.

Engel, C. and C.J. Kim (1999), "The long-run US/UK real exchange rate", Journal of Money, Credit and Banking, 31, 3, 335-356.

Frankel, J. (1979), "On the Mark: a theory of floating exchange rates based on real interest differentials", American Economic Review, 69, 610-622.

Froot, K.A. and K. Rogoff (1994), "Perspectives on PPP and long-run real exchange rates", NBER Working Paper no. 4952.

Gil-Alana, L. A. (1997), "Testing fractional integration in macroeconomic time series", $\mathrm{PhD}$ thesis, London School of Economics and Political Science.

Gil-Alana, L.A. (1999), "Testing fractional integration with monthly data", Economic Modelling, 16, 613-629.

Gil-Alana, L.A. and P.M. Robinson (1997), "Testing of unit root and other nonstationary hypotheses in macroeconomic time series", Journal of Econometrics, 80, 241-268.

Gil-Alana,L.A. and P.M. Robinson (2000), "Testing of seasonal fractional integration in UK and Japanese consumption and income", forthcoming in Journal of Applied Econometrics.

Granger, C.W.J. and R. Joyeux (1980), “An introduction to long memory time series models and fractional differencing”, Journal of Time Series Analysis, 1, 1, 15-29.

Huizinga, J. (1987), "An empirical investigation of the long run behavior of real exchange rates”, Carnegie-Rochester Conference Series on Public Policy, 27, 149-215.

Isard, P. and S. Symanski (1996), "Long run movements in real exchange rates", ch.2 in T. Ito, P. Isard, S. Symanski and T. Bayoumi, Exchange Rate Movements and Their Impact on Trade and Investment in the APEC Region, Occasional Paper no. 145, IMF, Washington.

Ito, T., Isard, P. and S. Symanski (1996), "Economic growth and real exchange rate: an overview of the Balassa-Samuelson hypothesis in Asia", paper presented at the Seventh Annual NBER-EASE Conference on Changes in Exchange Rates in Rapidly Developing Countries: Theory, Practice, and Policy Issues, Hong Kong, June 19-22, 1996. 
Lothian, J.R. (1997), "Multi-country evidence on the behavior of purchasing power parity under the current float", Journal of International Money and Finance, 16, 1, 19-35.

Lothian, J.R. and M.P. Taylor (1996), "Real exchange rate behavior: the recent float from the perspective of the past two centuries", Journal of Political Economy, 104, 3, 488-509.

Lothian, J.R. and M.P. Taylor (1997), "Real exchange rate behavior", Journal of International Money and Finance, 16, 6, 945-954.

MacDonald, R. (1995), "Long-run exchange rate modeling - A survey of the recent evidence", IMF Staff Papers, 42, 3, 437-489.

MacDonald, R., Marsh, I.W. and J. Nagayasu (1997), "Revisiting the long-run relationship between real exchange rates and real interest rate differentials", ICMM Discussion Paper Series in Financial Economics, D.P. no.39, University of Strathclyde, Glasgow.

Marinucci, D. and P.M. Robinson (1998),"Semi-parametric frequency domain analysis of fractional cointegration", STICERD, London School of Economics, Discussion Paper Series, $E M / 98 / 348$.

Meese, R. and K. Rogoff (1988), "Was it real? The exchange rate-interest differential relation over the modern floating-rate period", Journal of Finance, 43, 4, 933-948.

Michael, P., Nobay, A.R. and D.A. Peel (1997), "Transaction costs and nonlinear adjustment in real exchange rates: an empirical investigation", Journal of Political Economy, 105, 862879.

Mussa, M. (1982), “A model of exchange rate dynamics”, Journal of Political Economy, 90, 74-104.

Nelson, C.R. and C.I. Plosser (1982), "Trends and random walks in macroeconomic time series", Journal of Monetary Economics, 10, 139-162.

O'Connell, P.G.J. (1998), "Market frictions and relative traded goods prices", Journal of International Money and Finance, 17, 71-95.

Phillips, P.C.B. and P. Perron (1988), "Testing for a unit root in a time series regression", Biometrika, 75, 335-346.

Robinson, P.M. (1994), "Efficient tests of nonstationary hypotheses", Journal of the American Statistical Association, 89, 1420-1437.

Robinson, P.M. (1995a), "Log-periodogram regression of time series with long-range dependence", Annals of Statistics, 23, 1048-1072.

Robinson, P.M. (1995b), "Gaussian semiparametric estimation of long-range dependence", Annals of Statistics, 23, 1630-1661.

Rogoff, K. (1996), "The purchasing power parity puzzle", Journal of Economic Literature, 34, 2, 647-668. 
Samuelson, P. (1964), "Theoretical notes on trade problems", Review of Economics and Statistics, 46, 145-154.

Sowell, F. (1992), "Maximum likelihood estimation of stationary univariate fractionally integrated time series models, Journal of Econometrics, 53, 165-188.

Stock, J.H. (1987), "Asymptotic properties of least squares estimators of cointegrating vectors", Econometrica, 55, 1035-1056.

Taylor, M.P. and D.A. Peel (2000), "Nonlinear adjustment, long-run equilibrium and exchange rate fundamentals", Journal of International Money and Finance, 19, 33-53.

Wu, Y. and H. Zhang (1996), "Mean reversion in interest rates: new evidence from a panel of OECD countries”, Journal of Money, Credit and Banking, 28, 4, 604-621. 
TABLE 1

\begin{tabular}{|c|c|c|c|c|c|c|c|c|c|}
\hline Best model specificat & $\begin{array}{r}\text { each se } \\
A\end{array}$ & & d, & dels & & & & & \\
\hline & ARFIMA & & & & parame & & & paran & \\
\hline Series & $(p, d, q)$ & $t_{d=0}$ & $t_{d=1}$ & $\phi_{1}$ & $\phi_{2}$ & $\phi_{3}$ & $\theta_{1}$ & $\theta_{2}$ & $\theta_{3}$ \\
\hline $\begin{array}{c}\text { DM / Dollar real exchange } \\
\text { rate }\end{array}$ & $(0,0.98,1)$ & 8.16 & $-0.16^{\prime}$ & 0.41 & --- & --- & --- & --- & --- \\
\hline $\begin{array}{c}\text { Yen / Dollar exchange rate } \\
\text { (AIC) }\end{array}$ & $(2,0.94,3)$ & 2.93 & $-0.18^{\prime}$ & 0.83 & -0.53 & --- & -0.47 & 0.33 & 0.34 \\
\hline $\begin{array}{c}\text { Yen / Dollar exchange rate } \\
\text { (SIC) }\end{array}$ & $(0,1.29,0)$ & 12.9 & 2.90 & --- & --- & --- & --- & --- & --- \\
\hline $\begin{array}{c}\text { Labour productivity } \\
\text { differentials US / Germany }\end{array}$ & $(0,1.12,0)$ & 14.0 & $1.50^{\prime}$ & --- & --- & --- & --- & --- & --- \\
\hline $\begin{array}{c}\text { Labour productivity } \\
\text { differentials US / Japan }\end{array}$ & $(2,1.60,2)$ & 8.42 & 3.15 & 0.20 & -0.30 & --- & -0.17 & 1.10 & --- \\
\hline $\begin{array}{c}\text { Interest rate differentials } \\
\text { US / Germany }\end{array}$ & $(0,1.17,0)$ & 11.7 & $1.70^{\prime}$ & --- & --- & -- & --- & --- & --- \\
\hline $\begin{array}{c}\text { Interest rate differentials } \\
\text { US / Japan }\end{array}$ & $(0,1.16,0)$ & 11.6 & $1.60^{\prime}$ & --- & --- & -- & --- & --- & --- \\
\hline
\end{tabular}

*. ': Non-rejection values of the null hypothesis of a unit root, i.e., $d=1$. 


\begin{tabular}{|c|c|c|c|c|c|}
\hline \multicolumn{6}{|c|}{ TABLE 2} \\
\hline \multicolumn{6}{|c|}{ Testing the order of integration of the $\mathrm{DM} /$ dollar real exchange rate } \\
\hline & \multicolumn{5}{|c|}{$\mathrm{v}_{\mathrm{t}}$ disturbances } \\
\hline Values of $d$ & White noise & $\mathrm{AR}(1)$ & $\mathrm{AR}(2)$ & Seasonal AR(1) & Seasonal AR(2) \\
\hline 0 & 20.01 & 3.96 & 3.50 & 9.22 & 7.53 \\
\hline 0.25 & 13.90 & 3.01 & 2.68 & 4.52 & 4.30 \\
\hline 0.50 & 8.58 & 2.45 & 2.61 & 2.42 & 2.62 \\
\hline 0.75 & 3.20 & 1.88 & $1.61^{\prime}$ & $0.63^{\prime}$ & $0.48^{\prime}$ \\
\hline 1.00 & $-0.51^{\prime}$ & $-1.23^{\prime}$ & 0.45 & $-0.57^{\prime}$ & $-0.56^{\prime}$ \\
\hline 1.25 & -2.49 & -1.90 & $-0.55^{\prime}$ & -2.52 & -2.56 \\
\hline 1.50 & -3.52 & -2.55 & -1.94 & -3.59 & -3.62 \\
\hline 1.75 & -4.11 & -2.91 & -2.08 & -4.15 & -4.16 \\
\hline 2.00 & -4.48 & -3.17 & -2.19 & -4.51 & -4.51 \\
\hline
\end{tabular}

\begin{tabular}{|c|c|c|c|c|c|}
\hline \multicolumn{6}{|c|}{ TABLE 3} \\
\hline \multicolumn{6}{|c|}{ Testing the order of integration of the yen/dollar real exchange rate } \\
\hline & \multicolumn{5}{|c|}{$\mathrm{V}_{\mathrm{t}}$ disturbances } \\
\hline Values of d & White noise & $\mathrm{AR}(1)$ & $\mathrm{AR}(2)$ & Seasonal AR(1) & Seasonal AR(2) \\
\hline 0 & 19.46 & 4.64 & 5.73 & 9.17 & 6.59 \\
\hline 0.25 & 15.43 & 2.50 & 2.77 & 5.74 & 4.43 \\
\hline 0.50 & 9.80 & 1.97 & 2.08 & 3.62 & 3.27 \\
\hline 0.75 & 3.91 & $1.05^{\prime}$ & $1.39^{\prime}$ & 2.35 & 2.32 \\
\hline 1.00 & $-0.10 '$ & $-\mathbf{0 . 8 5}$ & 0.87 & -0.08 & -0.07 \\
\hline 1.25 & -2.26 & $-1.26^{\prime}$ & $-1.62^{\prime}$ & -2.28 & -2.29 \\
\hline 1.50 & -3.38 & -2.10 & -1.98 & -3.45 & -3.45 \\
\hline 1.75 & -4.01 & -2.86 & -2.56 & -4.07 & -4.07 \\
\hline 2.00 & -4.41 & -3.48 & -3.25 & -4.46 & -4.46 \\
\hline
\end{tabular}




\begin{tabular}{|c|c|c|c|c|c|}
\hline \multicolumn{6}{|c|}{ TABLE 4} \\
\hline \multicolumn{6}{|c|}{ Testing the order of integration of the labour productivity differentials in US / Germany } \\
\hline & \multicolumn{5}{|c|}{$\mathrm{V}_{\mathrm{t}}$ disturbances } \\
\hline Values of $d$ & White noise & $\mathrm{AR}(1)$ & $\mathrm{AR}(2)$ & Seasonal AR(1) & Seasonal AR(2) \\
\hline 0 & 16.85 & 4.32 & 3.22 & 7.14 & 7.94 \\
\hline 0.25 & 12.51 & 3.37 & 2.91 & 4.47 & 7.73 \\
\hline 0.50 & 7.15 & 3.02 & 2.46 & 2.54 & 6.36 \\
\hline 0.75 & 2.33 & 2.46 & $1.06^{\prime}$ & $1.49^{\prime}$ & 3.96 \\
\hline 1.00 & $-0.72^{\prime}$ & $0.53^{\prime}$ & 0.08 & -0.64 & 0.93 \\
\hline 1.25 & -2.39 & $1.48^{\prime}$ & -1.69 & -2.44 & -1.93 \\
\hline 1.50 & -3.33 & -2.57 & -2.70 & -3.40 & -3.32 \\
\hline 1.75 & -3.89 & -3.04 & -3.05 & -3.95 & -3.92 \\
\hline 2.00 & -4.26 & -3.36 & -3.24 & -4.31 & -4.29 \\
\hline
\end{tabular}

\begin{tabular}{|c|c|c|c|c|c|}
\hline \multicolumn{6}{|c|}{ TABLE 5} \\
\hline \multicolumn{6}{|c|}{ Testing the order of integration of the labour productivity differentials in US / Japan } \\
\hline & \multicolumn{5}{|c|}{$\mathrm{V}_{\mathrm{t}}$ disturbances } \\
\hline Values of d & White noise & $\mathrm{AR}(1)$ & $\mathrm{AR}(2)$ & Seasonal AR(1) & Seasonal AR(2) \\
\hline 0 & 17.82 & 5.18 & 3.18 & 8.25 & 7.79 \\
\hline 0.25 & 13.70 & 4.45 & 2.82 & 4.90 & 7.31 \\
\hline 0.50 & 8.56 & 4.13 & 2.09 & 2.62 & 4.38 \\
\hline 0.75 & 3.30 & 3.91 & 1.99 & $0.68^{\prime}$ & $1.56^{\prime}$ \\
\hline 1.00 & -0.30 & 3.48 & $1.43^{\prime}$ & $-0.46^{\prime}$ & $-0.47^{\prime}$ \\
\hline 1.25 & -2.23 & $1.08^{\prime}$ & $1.08^{\prime}$ & -2.27 & -2.32 \\
\hline 1.50 & -3.27 & $-0.67^{\prime}$ & -0.89 & -3.37 & -3.42 \\
\hline 1.75 & -3.87 & -1.83 & -2.11 & -3.92 & -3.93 \\
\hline 2.00 & -4.26 & -2.62 & -2.15 & -4.26 & -4.25 \\
\hline
\end{tabular}




\begin{tabular}{|c|c|c|c|c|c|}
\hline \multicolumn{6}{|c|}{ TABLE 6} \\
\hline \multicolumn{6}{|c|}{ Testing the order of integration of the real interest differentials in US / Germany } \\
\hline & \multicolumn{5}{|c|}{$\mathrm{v}_{\mathrm{t}}$ disturbances } \\
\hline Values of $d$ & White noise & $\mathrm{AR}(1)$ & $\mathrm{AR}(2)$ & Seasonal AR(1) & Seasonal AR(2) \\
\hline 0 & 13.98 & 2.88 & 2.19 & 9.69 & 7.12 \\
\hline 0.25 & 11.70 & 2.23 & 2.05 & 7.99 & 7.00 \\
\hline 0.50 & 8.43 & 1.76 & 1.69 & 6.56 & 6.38 \\
\hline 0.75 & 4.62 & -1.05 & $1.29^{\prime}$ & 4.84 & 4.93 \\
\hline 1.00 & $1.29^{\prime}$ & $-1.06^{\prime}$ & 0.67 & 2.33 & 2.62 \\
\hline 1.25 & $-0.99^{\prime}$ & $-1.15^{\prime}$ & $-0.91^{\prime}$ & $-0.22^{\prime}$ & $-0.01^{\prime}$ \\
\hline 1.50 & -2.38 & -2.58 & -1.79 & -2.01 & -2.00 \\
\hline 1.75 & -3.22 & -3.19 & -1.99 & -3.05 & -3.14 \\
\hline 2.00 & -3.75 & -3.65 & -2.10 & -3.64 & -3.76 \\
\hline
\end{tabular}

\begin{tabular}{|c|c|c|c|c|c|}
\hline \multicolumn{6}{|c|}{ TABLE 7} \\
\hline \multicolumn{6}{|c|}{ Testing the order of integration of the real interest differentials in US / Japan } \\
\hline & \multicolumn{5}{|c|}{$\mathrm{v}_{\mathrm{t}}$ disturbances } \\
\hline Values of $d$ & White noise & $\mathrm{AR}(1)$ & $\mathrm{AR}(2)$ & Seasonal AR(1) & Seasonal AR(2) \\
\hline 0 & 13.37 & 2.71 & 3.19 & 10.11 & 8.81 \\
\hline 0.25 & 10.40 & $1.32^{\prime}$ & 2.36 & 8.47 & 7.89 \\
\hline 0.50 & 6.92 & $1.29^{\prime}$ & $1.12^{\prime}$ & 6.37 & 6.36 \\
\hline 0.75 & 3.44 & 0.80 ' & 0.73, & 3.74 & 3.98 \\
\hline 1.00 & 0.57 & $-0.97^{\prime}$ & $-0.74^{\prime}$ & 1.01 ' & 1.15 \\
\hline 1.25 & $-1.49^{\prime}$ & $-1.06^{\prime}$ & -1.74 & $-1.15^{\prime}$ & $-1.16^{\prime}$ \\
\hline 1.50 & -2.87 & $-1.44^{\prime}$ & -1.90 & -2.63 & -2.67 \\
\hline 1.75 & -3.75 & -2.16 & -2.12 & -3.57 & -3.62 \\
\hline 2.00 & -4.32 & -2.95 & -2.19 & -4.18 & -4.22 \\
\hline $\begin{array}{l}\text { ' } \text { Non-reject } \\
\text { across the di }\end{array}$ & $\begin{array}{l}\text { es of the } n \\
\text { alues of } d\end{array}$ & thesis a & $5 \%$ sigr & e level. In bolc & ne smallest value \\
\hline
\end{tabular}


TABLE 8

Testing the order of integration on the residuals of the cointegrating regression (including interest rate and productivity differentials) for Germany

\begin{tabular}{|c|c|c|c|c|c|}
\hline & \multicolumn{5}{|c|}{$\mathrm{V}_{\mathrm{t}}$ disturbances } \\
\hline Values of d & White noise & $\mathrm{AR}(1)$ & $\mathrm{AR}(2)$ & Seasonal AR(1) & Seasonal AR(2) \\
\hline 0 & 17.78 & $0.72^{\prime}$ & 2.86 & 9.47 & 8.20 \\
\hline 0.10 & 16.36 & $\mathbf{- 0 . 2 6} \boldsymbol{\prime}^{\prime}$ & 2.84 & 8.49 & 7.82 \\
\hline 0.20 & 14.47 & $-0.94^{\prime}$ & 2.53 & 7.64 & 7.35 \\
\hline 0.30 & 12.16 & $-1.34^{\prime}$ & $1.95^{\prime}$ & 6.85 & 6.77 \\
\hline 0.40 & 9.61 & $-1.34^{\prime}$ & $1.82^{\prime}$ & 5.98 & 6.02 \\
\hline 0.50 & 7.07 & $-1.55^{\prime}$ & $\mathbf{- 0 . 9 8}$, & 4.93 & 5.06 \\
\hline 0.60 & 4.79 & -2.12 & $-1.28^{\prime}$ & 3.70 & 3.86 \\
\hline 0.70 & 2.88 & -2.17 & -2.08 & 2.40 & 2.53 \\
\hline 0.80 & $1.37^{\prime}$ & -2.33 & -2.13 & 1.19 & $1.26^{\prime}$ \\
\hline 0.90 & $\mathbf{0 . 2 1}$ & -2.87 & -2.32 & $\mathbf{0 . 1 4}$ & $\mathbf{0 . 1 6}$ \\
\hline 1.00 & $-0.67^{\prime}$ & -3.42 & -2.59 & -0.70 & $-0.72^{\prime}$ \\
\hline
\end{tabular}

' $:$ Non-rejection values of the null hypothesis at the $95 \%$ significance level. In bold: The smallest value across the different values of $d$.

\begin{tabular}{|c|c|c|c|c|c|}
\hline \multicolumn{6}{|c|}{ TABLE 9} \\
\hline \multicolumn{6}{|c|}{$\begin{array}{l}\text { Testing the order of integration on the residuals of the cointegrating regression } \\
\text { (including interest rate and productivity differentials) for Japan }\end{array}$} \\
\hline & \multicolumn{5}{|c|}{$\mathrm{v}_{\mathrm{t}}$ disturbances } \\
\hline Values of d & White noise & $\operatorname{AR}(1)$ & $\mathrm{AR}(2)$ & Seasonal AR(1) & Seasonal AR(2) \\
\hline 0 & 16.18 & 2.30 & 2.70 & 10.02 & 9.66 \\
\hline 0.10 & 14.99 & $1.34^{\prime}$ & $1.66^{\prime}$ & 9.69 & 9.53 \\
\hline 0.20 & 13.57 & $0.46^{\prime}$ & $0.77^{\prime}$ & 9.29 & 9.25 \\
\hline 0.30 & 11.94 & -0.38, & $-0.40^{\prime}$ & 8.77 & 8.80 \\
\hline 0.40 & 10.15 & $-1.28^{\prime}$ & $-1.32^{\prime}$ & 8.06 & 8.13 \\
\hline 0.50 & 8.29 & $-1.44^{\prime}$ & -2.01 & 7.13 & 7.20 \\
\hline 0.60 & 6.45 & $-2.24^{\prime}$ & -2.34 & 5.97 & 6.01 \\
\hline 0.70 & 4.73 & -2.43 & -2.65 & 4.66 & 4.63 \\
\hline 0.80 & 3.18 & -2.76 & -2.71 & 3.29 & 3.21 \\
\hline 0.90 & $1.83^{\prime}$ & -2.98 & -3.05 & 1.97 & $1.87^{\prime}$ \\
\hline 1.00 & 0.68 & -3.07 & -3.85 & 0.79 & 0.71 , \\
\hline
\end{tabular}

